\title{
Paediatric use of flecainide in supraventricular tachycardia: clinical efficacy and pharmacokinetics
}

\author{
JANICE A TILL, * ELLIOT A SHINEBOURNE, * EDWARD ROWLAND, $\dagger$ \\ DAVID E WARD, $\ddagger$ RUPINDER BHAMRA,§ PER HAGA, * ATHOLL JOHNSTON, \\ DAVID W HOLT $\S$
}

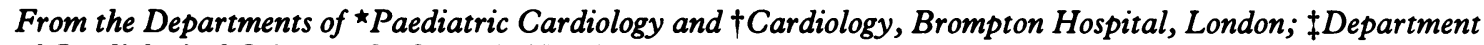
of Cardiological Sciences, St George’s Hospital, London; §Poisons Unit, Guy's Hospital, London; and TDepartment of Clinical Pharmacology, St Bartholomew's Hospital, London

SUMMARY Twenty three children with recurrent supraventricular tachycardia were treated with flecainide. Twenty one of these received intravenous treatment during an attack $(2 \mathrm{mg} / \mathrm{kg}$ over 10 minutes). The tachycardia was terminated in 17. After an intravenous bolus of flecainide, blood samples were drawn at regular intervals for analysis of flecainide concentration over 48 hours. Pharmacokinetic variables were calculated-median terminal half life 7.5 hours, median volume of distribution $6.21 / \mathrm{kg}$, and median plasma clearance $7.2 \mathrm{ml} / \mathrm{min} / \mathrm{kg}$. There was a significant correlation between half life and age. Twenty of the children received long term treatment with an oral preparation of flecainide to prevent further attacks. Twelve had no further attacks and 16 were considered to have good control. Two children suffered potentially serious arrhythmogenic effects soon after the start of oral treatment and flecainide had to be stopped. During oral treatment regular blood samples were drawn and plasma concentrations were analysed to assess the therapeutic range. This did not differ substantially from that proposed in adults (400-800 $\mu \mathrm{g} / 1)$. Eight children were electively withdrawn from oral flecainide to see whether they really needed it. Blood samples for measurement of flecainide concentration were drawn after their last oral dose. Pharmacokinetic variables were calculated: time to maximum concentration 2 hours, median terminal half life 7.9 hours. For the combined data from patients receiving intravenous and oral treatment there was a significant correlation between elimination half life and age. An intravenous dose of $2 \mathrm{mg} / \mathrm{kg}$ over at least 10 minutes and an initial oral dose of $6 \mathrm{mg} / \mathrm{kg} /$ day in three divided doses is recommended. Treatment should be started in hospital so that children in whom the drug may be arrhythmogenic can be identified and plasma concentrations measured to identify patients in whom lack of efficacy is caused by underdosage.

Flecainide is a new class lc antiarrhythmic drug that has recently been introduced into paediatric practice. It acts on the fast sodium channel. It slows conduction throughout the conduction system and has its greatest effect on the His bundle. The refractory period of most tissues is only slightly prolonged except that of accessory pathways, where this effect is more pronounced. ${ }^{1}$ In adults flecainide was highly

Requests for reprints to Dr Janice A Till, Department of Paediatric Cardiology, Brompton Hospital, Fulham Road, London SW3 6HP.

Accepted for publication 6 February 1989 effective in the treatment of both supraventricular and ventricular arrhythmias. ${ }^{2}$ Side effects are not uncommon but are generally benign and dose dependent. However, flecainide, like other potent antiarrhythmic agents, may cause arrhythmogenic effects with potentially serious consequences. ${ }^{3}$

As with many new drugs flecainide has been given to children in doses modified from those that were successful in adult patients without examination of its pharmacokinetics in children. ${ }^{45} \mathrm{~A}$ knowledge of the pharmacokinetics of flecainide in children may help to prevent unwanted effects of the drug and is essential if this potent drug is to be used to its full advantage in children. 
Table 1 Patient characteristics

\begin{tabular}{|c|c|c|c|c|c|c|}
\hline Case & Age & Sex & Diagnosis & Previous treatment & Cardiac diagnosis & Frequency \\
\hline $\begin{array}{l}1 \\
2 \\
3^{\star} \\
4 \\
5 \\
6 \\
7 \\
8 \\
9 \\
10 \\
11 \\
12^{\star} \\
13^{\star} \\
14 \\
15^{\star} \\
16 \\
17 \\
18 \\
19^{\star} \\
20 \\
21 \\
22^{\star} \\
23\end{array}$ & $\begin{array}{l}7 \text { day } \\
8 \text { day } \\
1 \text { mnth } 7 \text { day } \\
1 \text { mnth } 14 \text { day } \\
1 \text { mnth } 15 \text { day } \\
1 \text { mnth } 17 \text { day } \\
2 \text { mnth } \\
2 \text { mnth } 2 \text { day } \\
2 \text { mnth } 7 \text { day } \\
3 \text { mnth } \\
9 \text { mnth } 18 \text { day } \\
2 \text { yr } \\
3 \text { yr } \\
8 \text { yr } \\
8 \text { yr } 8 \text { mnth } 15 \text { day } \\
10 \text { yr } 9 \text { mnth } \\
10 \text { yr } 10 \text { mnth } \\
10 \text { yr } 11 \text { mnth } \\
11 \text { yr } 6 \text { mnth } \\
12 \text { yr } 3 \text { mnth } \\
12 \text { yr } 6 \text { mnth } \\
13 \text { yr } 9 \text { mnth } \\
17 \text { yr }\end{array}$ & $\begin{array}{l}\mathbf{M} \\
\mathbf{F} \\
\mathbf{M} \\
\mathbf{M} \\
\mathbf{F} \\
\mathbf{M} \\
\mathbf{M} \\
\mathbf{M} \\
\mathbf{M} \\
\mathbf{F} \\
\mathbf{F} \\
\mathbf{F} \\
\mathbf{F} \\
\mathbf{F} \\
\mathbf{M} \\
\mathbf{F} \\
\mathbf{F} \\
\mathbf{F} \\
\mathbf{M} \\
\mathbf{F} \\
\mathbf{F} \\
\mathbf{F} \\
\mathbf{M}\end{array}$ & $\begin{array}{l}\text { HBT } \\
\text { AVRT/oc } \\
\text { AVRTc } \\
\text { AVRTc } \\
\text { AVRTc } \\
\text { AVRTc } \\
\text { AVNRT } \\
\text { AVRTc } \\
\text { AVRTo } \\
\text { AVRTc } \\
\text { AVNRT } \\
\text { A FL } \\
\text { AVNRT } \\
\text { AVRTc } \\
\text { AVNRT } \\
\text { AVNRT } \\
\text { AVRTc } \\
\text { AVRTc } \\
\text { AVRTo } \\
\text { AVRTo } \\
\text { AVRTo } \\
\text { EAT } \\
\text { EAT }\end{array}$ & $\begin{array}{l}\text { dig, ado, ver } \\
\text { ado } \\
\text { ver, dis, amio } \\
\text { dig, ado, ver } \\
\text { dig, ado, ver } \\
\text { dig, ver } \\
\text { dig, ado } \\
\text { dig, ado } \\
\text { dig, ver } \\
\text { dig } \\
\text { dig } \\
\text { dig, amio } \\
\text { dig, prop } \\
\text { ver, prop } \\
\text { dig, prop } \\
\text { dig, ver, prop } \\
\text { dig, prop } \\
\text { ver } \\
\text { prop } \\
\text { dig, ver } \\
\text { prop, nad } \\
\text { ver, dis } \\
\text { dig, ver }\end{array}$ & $\begin{array}{l}\text { Myocardial necrosis } \\
\text { N } \\
\text { N } \\
\text { N } \\
\text { Multiple intracardiac tumours } \\
\text { N } \\
\text { TGA } \\
\mathbf{N} \\
\mathbf{N} \\
\mathbf{N} \\
\mathbf{N} \\
\text { ASD } \\
\mathbf{N} \\
\mathbf{N} \\
\mathbf{N} \\
\mathbf{N} \\
\mathbf{N} \\
\mathbf{N} \\
\mathbf{N} \\
\text { VSD } \\
\mathbf{N} \\
\mathbf{N} \\
\text { DILV }\end{array}$ & $\begin{array}{l}\text { Incessant } \\
\text { Daily } \\
\text { Daily } \\
\text { 1/week } \\
\text { 4/week } \\
\text { Daily } \\
\text { Repetitive } \\
\text { Repetitive } \\
\text { 1/week } \\
\text { 1/mnth } \\
\text { 1/mnth } \\
\text { Incessant } \\
\text { Repetitive } \\
\text { 6/mnth } \\
5 / \text { yr } \\
\text { Daily } \\
\text { 1/mnth } \\
5 / \text { yr } \\
2 / \text { yr } \\
\text { 1/mnth } \\
\text { 1/mnth } \\
\text { Incessant } \\
\text { 2/yr }\end{array}$ \\
\hline
\end{tabular}

*Patients reported in an earlier study. ${ }^{4}$

HBT, His bundle tachycardia; AVRT, atrioventricular re-entry tachycardia; c, concealed pre-excitation; o, overt pre-excitation; AVNRT, atrioventricular nodal re-entry tachycardia; EAT, ectopic atrial tachycardia; A FL atrial flutter; dig, digoxin; ver, verapamil; ado, adenosine prop, propranolol; dis, disopyramide; amio, amiodarone; nad, nadolol; TGA, complete transposition of the great arteries; ASD, atrial septal defect; VSD, ventricular septal defect; DILV, double inlet left ventricle; N, normal.

\section{Patients and methods}

Twenty three consecutive children with documented recurrent supraventricular tachycardia aged between eight days and 17 years (median two years) were treated with flecainide. Six of the children (patients 3 , $12,13,15,19$, and 22 (table 1)) have already been reported by our group 4 in a study to assess efficacy of flecainide in terminating their acute arrhythmias. We have included them in the present study to report their pharmacokinetics and subsequent long term follow up. In most children the diagnosis could be made from analysis of the surface electrocardiogram during tachycardia and sinus rhythm. In nine of the children the diagnosis was confirmed by electrophysiological study. In total, 14 children had atrioventricular re-entry tachycardia-associated with overt pre-excitation in five and concealed in 9. Five had atrioventricular nodal re-entry tachycardia, two had ectopic atrial tachycardia, one His bundle tachycardia, and one atrial flutter. Seventeen of the children had structurally normal hearts. Of the other six, three had had operations for congenital cardiac anomalies: one an anatomical correction for atrioventricular concordance, ventriculo-arterial discordance (complete transposition); one a Kreutzer modification of the Fontan procedure for double inlet left ventricle, subpulmonary and pulmonary stenosis; and one closure of a ventricular septal defect (table 1). The infant with atrial flutter had an atrial secundum defect, the neonate with His bundle tachycardia had poor ventricular function and at necropsy was found to have widespread areas of myocardial necrosis of unknown cause, and one child with atrioventricular re-entry tachycardia had multiple intracardiac tumours. In all cases the attacks of tachycardia were recurrent or incessant and were refractory to conventional drug treatment. In 16 children the attack of supraventricular tachycardia that was treated intravenously occurred spontaneously; in five it was induced during an electrophysiological study. Children with evidence of sick sinus syndrome were excluded from the study as were children with evidence of clinical or biochemical renal or liver failure. Informed parental and, where appropriate, the patient's consent was obtained in each case and the ethics committees of both St George's and the Brompton Hospitals approved the trial.

\section{METHODS}

Flecainide (Tambocor, Riker Laboratories) was given intravenously at a dose of $2 \mathrm{mg} / \mathrm{kg}$ over 10 minutes during supraventricular tachycardia to 21 patients. The standard intravenous preparation of flecainide acetate $(10 \mathrm{mg} / \mathrm{ml})$ was used. Throughout drug administration the electrocardiogram was recorded and blood pressure monitored either by direct intra-arterial measurement or frequent sphygmomanometer readings. After drug adminis- 
tration blood samples $(0.5 \mathrm{ml})$ were collected at regular intervals for 48 hours or until further episodes of tachycardia requiring treatment occurred. Where possible blood was sampled with a separate indwelling venous cannula. When this was not possible, in small neonates with difficult venous access, blood was sampled through the cannula used for intravenous drug administration, with vigorous flushing between samples. Plasma was then stored at $-20^{\circ} \mathrm{C}$ before the measurement of plasma flecainide concentrations.

Oral flecainide was started in 20 patients at least 48 hours after the intravenous bolus for the prevention of recurrent attacks. Wherever possible standard tablets (100 mg) were used (that is if doses of $100 \mathrm{mg}$ or $50 \mathrm{mg}$ were required). These tablets are scored and can be halved easily. For the smaller children we used a liquid formulation of flecainide based on the intravenous preparation and prepared by the pharmacies of the Brompton and St George's Hospitals. Stability studies performed by Riker confirmed a stable formulation with a shelf life of at least three months. Oral medication was started in hospital. The dose used for long term treatment was the minimum required for suppression of arrhythmia during hospital stay or, if this could not be assessed because arrhythmia was infrequent, a dose required to achieve a pre-dose plasma flecainide concentration greater than $350 \mu \mathrm{g} / 1$ was used.

The children were then followed as outpatients and at each hospital visit attacks of tachycardia were documented, 12 lead electrocardiogram recorded, and a pre-dose blood sample collected for the measurement of plasma flecainide. If attacks were suspected, confirmation was sought with Holter monitor or Cardiomemo recordings and parents were encouraged to keep an accurate diary of events.

In a small group of children oral flecainide was electively withdrawn after long term oral treatment because it was no longer required. Blood samples were collected via an indwelling intravenous cannula at frequent intervals for $48 \mathrm{~h}$ after an oral dose of flecainide for the measurement of pharmacokinetic variables.

\section{DRUG AND DATA ANALYSIS}

Plasma flecainide concentrations were measured by high performance liquid chromatography..$^{\circ}$ Pharmacokinetic variables were derived from the computer program STRIPE. ${ }^{7}$

\section{Results}

\section{INTRAVENOUS FLECAINIDE: EFFICACY}

Two children did not receive intravenous treatment because their acute attack terminated spontaneously. Of the remaining 21 children, tachycardia was terminated in seventeen. The mean time to termination was 5.3 minutes (range 1.5-10 minutes). In the neonate with His bundle tachycardia flecainide resulted in a halving of the tachycardia rate with possible 2:1 exit block from the automatic focus eight minutes after the start of the flecainide bolus-a favourable result. In one child with atrioventricular re-entry tachycardia, one with ectopic atrial tachycardia, and another with atrial flutter, flecainide caused slowing of the tachycardia rate but failed to terminate the arrhythmia.
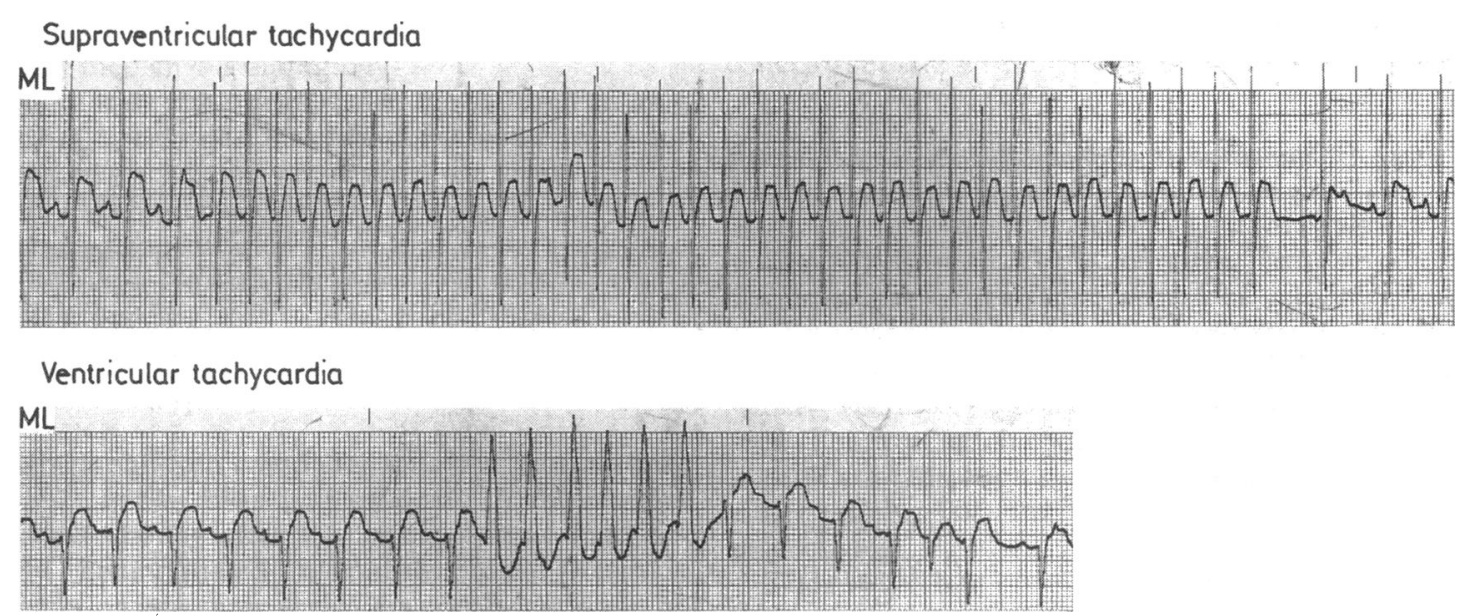

Fig 1 Monitor lead from a neonate with atrioventricular nodal re-entry tachycardia. Monitor lead from the same neonate after treatment with flecainide showing non-sustained ventricular tachycardia-a possible arrhythmogenic effect of flecainide. 
Side effects during intravenous administration were few. The infant who had undergone anatomical correction suffered an episode of hypotension for 3060 minutes during and after drug treatment. The systemic blood pressure fell $15 \mathrm{~mm} \mathrm{Hg}$ (from $85 \mathrm{~mm} \mathrm{Hg}$ to $70 \mathrm{~mm} \mathrm{Hg}$ ). No treatment was required for this and the blood pressure recovered spontaneously. Hypotension was not recorded in any other child during the study despite three other children being in severe cardiac failure (patients 1,3 , and 8 ) before flecainide was given. Two children reported a sensation of nausea and one vomited. These effects ceased within 15 minutes of drug administration.

Widening of the QRS complexes was seen after infusion, as expected from the known electrophysiological actions of the drug. No arrhythmogenesis occurred after intravenous flecainide.

\section{ORAL FLECAINIDE: EFFICACY}

Twenty of the 23 children received oral flecainide for long term control. Three children who had received intravenous flecainide did not enter this part of the study. The neonate with His bundle tachycardia, despite adequate control of heart rate, died with failing cardiac function two days after the intravenous dose of flecainide. Patient 2 had frequently recurring attacks of supraventricular tachycardia that were not terminated with intravenous flecainide. This child was not given a trial of oral flecainide because increasing cardiac failure necessitated more immediate treatment; intravenous amiodarone was finally successful in preventing further attacks. The third child who did not receive oral flecainide (patient 21) had in the past been partially controlled with nadolol and, despite rapid termination of arrhythmia with flecainide, her physician requested that she remain on nadolol.

In two patients flecainide had to be stopped shortly after oral treatment was started in hospital. In patient 8 oral flecainide was stopped after three days. This patient had responded well to intravenous flecainide but further administration of oral flecainide failed to prevent frequent attacks. The tachycardia rate slowed but remained incessant. Flecainide was therefore stopped and the attacks were later controlled with a combination of amiodarone and digoxin. Patient 7 developed episodes of ventricular tachycardia four days after oral treatment was started. These were of short duration and terminated spontaneously (fig 1 ). He was receiving a dose of 8.4 $\mathrm{mg} / \mathrm{kg} /$ day and had a trough concentration of $570 \mu \mathrm{g} / 1$. On withdrawal of flecainide his attacks of ventricular tachycardia resolved.

The remaining 18 children received long term oral flecainide. They have been followed up for $2-55$ months (median 20 months). Twelve children have had no further attacks. Four others have been well controlled, with only one or two attacks of short duration per year. These attacks were often associated with failure to take medication. One child with atrioventricular re-entry tachycardia continued on oral flecainide for two months with poor control. However, no other agent could be found that achieved better control, and finally she underwent successful operation for resection of an accessory pathway when she was three months old. Of note are two children whose supraventricular tachycardia failed to stop in response to intravenous flecainide but who were well controlled, with no further attacks, when they were being treated with oral flecainide.

Long term pre-dose plasma flecainide concentrations associated with control varied from 170 to 935

Table 2 Pharmacokinetic variables after intravenous flecainide (2 mg/kg)

\begin{tabular}{|c|c|c|c|c|c|c|}
\hline Case & Age & Weight ( $\mathrm{kg})$ & Height $(\mathrm{cm})$ & $V S S(l / k g)$ & $\begin{array}{l}\text { Total plasma clearance } \\
(\mathrm{ml} / \mathrm{min} / \mathrm{kg})\end{array}$ & $T 1 / 2$ elimination $(h)$ \\
\hline $\begin{array}{r}1 \\
3 \\
4 \\
7 \\
8 \\
10 \\
13 \\
15 \\
16 \\
17 \\
18 \\
21 \\
22 \\
23\end{array}$ & $\begin{array}{l}7 \text { day } \\
1 \text { mnth } 7 \text { day } \\
1 \text { mnth } 14 \text { day } \\
2 \text { mnth } \\
2 \text { mnth } 2 \text { day } \\
3 \text { mnth } \\
3 \text { yr } \\
8 \text { yr } 8 \text { mnth } 15 \text { day } \\
10 \text { yr } 9 \text { mnth } \\
10 \text { yr } 10 \text { mnth } \\
10 \text { yr } 11 \text { mnth } \\
12 \text { yr } 6 \text { mnth } \\
13 \text { yr } 9 \text { mnth } \\
17 \text { yr }\end{array}$ & $\begin{array}{r}2 \cdot 7 \\
4 \cdot 5 \\
4 \cdot 3 \\
2 \cdot 8 \\
3 \cdot 8 \\
6 \cdot 0 \\
14 \cdot 8 \\
37 \cdot 0 \\
33 \cdot 4 \\
30 \cdot 0 \\
33 \cdot 8 \\
47 \cdot 6 \\
40 \cdot 2 \\
50 \cdot 0\end{array}$ & $\begin{array}{r}49 \\
56 \\
55 \\
52 \\
51 \\
62 \\
92 \\
146 \\
138 \\
143 \\
143 \\
153 \\
162 \\
176\end{array}$ & $\begin{array}{l}8 \cdot 5 \\
6 \cdot 7 \\
8 \cdot 2 \\
9 \cdot 0 \\
6 \cdot 7 \\
3 \cdot 4 \\
1 \cdot 9 \\
5 \cdot 7 \\
5 \\
4 \cdot 7 \\
3 \cdot 5 \\
6 \cdot 8\end{array}$ & $\begin{array}{c}48 \cdot 2 \\
6 \cdot 7 \\
-18 \cdot 9 \\
9 \cdot 2 \\
10 \\
5 \cdot 4 \\
3 \cdot 0 \\
7 \\
8 \cdot 6 \\
6 \cdot 6 \\
4 \cdot 5 \\
7 \cdot 4\end{array}$ & $\begin{array}{c}3 \cdot 8 \\
10 \cdot 1 \\
5 \cdot 4 \\
5 \\
11 \cdot 6 \\
7 \cdot 5 \\
7 \cdot 5 \\
7 \cdot 2 \\
7 \cdot 3 \\
9 \\
6 \cdot 7 \\
8 \cdot 2 \\
9 \cdot 5 \\
10 \cdot 6\end{array}$ \\
\hline Median & 6 yr 4 mnth 15 day & $25 \cdot 7$ & 118 & $6 \cdot 2$ & $7 \cdot 2$ & $7 \cdot 5$ \\
\hline
\end{tabular}

The patient numbers correspond to those shown in table 1 . VSS, volume of distribution at steady state; $T 1 / 2$, half life. 
Table 3 Pharmacokinetic variables after the end of long term oral treatment

\begin{tabular}{|c|c|c|c|c|c|c|c|c|c|c|}
\hline Case & Age & $\begin{array}{l}W t \\
(\mathrm{~kg})\end{array}$ & $\begin{array}{l}H t \\
(\mathrm{~cm})\end{array}$ & $\begin{array}{l}\text { Surface } \\
\text { area }\left(m^{2}\right)\end{array}$ & $\begin{array}{l}\text { Total daily } \\
\text { dose (mg) }\end{array}$ & $\begin{array}{l}\text { Daily dose } \\
\text { (mg/kg) }\end{array}$ & $\begin{array}{l}\text { Daily dose } \\
\left(\mathrm{mg} / \mathrm{m}^{2}\right)\end{array}$ & $\begin{array}{l}C \max \\
(\mu g / l)\end{array}$ & $\underset{(h)}{T \max }$ & $\begin{array}{l}\text { Terminal elimination } \\
\text { half life }(h)\end{array}$ \\
\hline $\begin{array}{r}5 \\
3 \\
4 \\
11 \\
12 \\
14 \\
19 \\
18\end{array}$ & $\begin{array}{l}1 \text { mnth } 15 \text { day } \\
10 \mathrm{mnth} \\
1 \mathrm{yr} \\
1 \mathrm{yr} 6 \mathrm{mnth} \\
2 \mathrm{yr} 6 \mathrm{mnth} \\
8 \mathrm{yr} \\
11 \mathrm{yr} 6 \mathrm{mnth} \\
13 \mathrm{yr}\end{array}$ & $\begin{array}{c}2.95 \\
11.6 \\
11 \cdot 1 \\
9 \cdot 4 \\
9 \cdot 3 \\
26 \cdot 8 \\
46 \cdot 6 \\
37 \cdot 5\end{array}$ & $\begin{array}{l}48 \\
80 \\
77 \cdot 5 \\
77 \\
76 \\
133 \\
152 \\
152\end{array}$ & $\begin{array}{l}0.188 \\
0.475 \\
0.455 \\
0.435 \\
0.425 \\
1.16 \\
1.38 \\
1.27\end{array}$ & $\begin{array}{r}72 \\
54 \\
54 \\
75 \\
50 \\
150 \\
200 \\
300\end{array}$ & \begin{tabular}{c|}
24 \\
$4 \cdot 7$ \\
$4 \cdot 9$ \\
$8 \cdot 0$ \\
$5 \cdot 4$ \\
$5 \cdot 6$ \\
$4 \cdot 3$ \\
$8 \cdot 0$
\end{tabular} & $\begin{array}{l}383 \\
114 \\
119 \\
172 \\
118 \\
129 \\
145 \\
236\end{array}$ & $\begin{array}{l}873 \\
212 \\
228 \\
567 \\
400 \\
377 \\
558 \\
494\end{array}$ & $\begin{array}{l}4 \cdot 8 \\
1 \\
4 \\
2 \\
1 \cdot 3 \\
6 \\
2 \\
1\end{array}$ & $\begin{aligned} 5 \cdot 8 \\
6 \cdot 5 \\
4 \cdot 8 \\
6 \\
9 \cdot 2 \\
9 \cdot 4 \\
9 \cdot 6 \\
10 \cdot 5 \\
\end{aligned}$ \\
\hline \multicolumn{2}{|c|}{ Median 2 yr } & 10.3 & $77 \cdot 3$ & 0.465 & 74 & 5.5 & 137 & 389 & 2 & 7.9 \\
\hline
\end{tabular}

$\mathrm{C}$ max, maximum plasma concentration; $\mathrm{T}$ max, time to maximum plasma concentration. The patient numbers correspond to those shown in table 1 .

$\mu \mathrm{g} / 1$ (median plasma concentration $415 \mu \mathrm{g} / \mathrm{l}$ ). These corresponded to doses ranging from 3.6 to $11.1 \mathrm{mg} /$ $\mathrm{kg} /$ day (median $4.8 \mathrm{mg} / \mathrm{kg} /$ day).

There were few side effects in the children on long term oral flecainide. One child developed a persistent severe headache two weeks after the start of treatment. This resolved after a reduction in dose. Plasma flecainide concentration at the time of the symptoms was $840 \mu \mathrm{g} / 1$. No arrhythmogenic effects were noted in this group.

\section{PHARMACOKINETICS AFTER INTRAVENOUS FLECAINIDE}

Fourteen children completed this part of the study (table 2). In two cases (patients 4 and 16) the samples collected shortly after the infusion were inadvertently contaminated by intravenous flecainide preparation and these early data points could not be

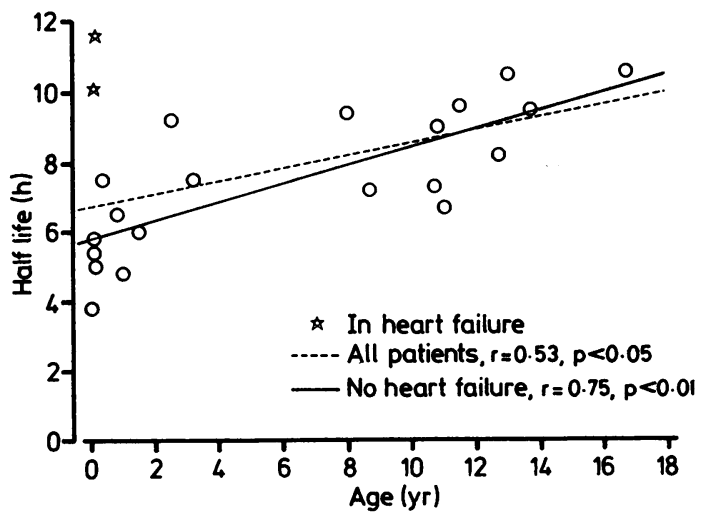

Fig 2 Correlation between elimination half life and age for combined data on intravenous and oral treatment. The correlation was improved by the omission of data from two patients in heart failure. used for pharmacokinetic analysis. In the remaining cases there was a good fit between plasma flecainide concentration and time points.

\section{PHARMACOKINETICS AFTER THE END OF ORAL FLECAINIDE}

Eight children underwent elective withdrawal of oral flecainide. Seven of the children had received flecainide for at least one year; one had received treatment for three weeks. Table 3 summarises the pharmacokinetic variables. Daily doses varied widely, both in relation to body weight and surface area. The correlation coefficients between maximum plasma concentration and daily dose calculated as either $\mathrm{mg} / \mathrm{kg}$ or $\mathrm{mg} / \mathrm{m}^{2}$ were 0.57 and 0.70 respectively.

The median half life of elimination after the end of long term flecainide treatment was not significantly different from that calculated after short term intravenous dosing ( $p<0.1$, Mann-Whitney $U$ test). For the combined data from patients receiving either intravenous or oral treatment there was a significant correlation between elimination half life and age $(r=0.53, p<0.05)$ (fig 2). This correlation was improved if the data for the two patients who were in heart failure while they were treated with intravenous flecainide (patients 3 and 8 ) were omitted $(r=0.75, p<0.01)$.

\section{Discussion}

Flecainide is a potent antiarrhythmic drug currently being used in children but the pharmacokinetics of flecainide in this age group have not yet been established. ${ }^{5}$ Their elucidation may help to prevent some of the side effects and allow the drug to be used more successfully. Efficacy of intravenous flecainide in our group of patients with refractory tachycardia 
was high, in accordance with other studies. Termination of sustained tachycardia occurred in 17 of 21 cases. Side effects occurred in three of these children but in only one child was this a potentially serious problem. Plasma concentrations immediately after intravenous treatment were high. Administration over a longer period would reduce these concentrations and potentially reduce the incidence and severity of side effects.

Efficacy after oral treatment in this group of children with resistant tachycardia was also high. Twelve of 20 children had no further attacks while 16 had good control. Two children had potentially serious arrhythmogenic effects while on oral treatment. In common with other studies both arrhythmogenic events occurred soon after the start of oral treatment, supporting the practice of starting treatment in hospital. The frequency of arrhythmogenesis in our small group was high. In studies of adults arrhythmogenesis was more common in those patients with left ventricular dysfunction ${ }^{8}$ and in those treated for ventricular arrhythmia. ${ }^{9}$ The two children who had these effects in our group did not belong to either of these categories, nor was the concentration of flecainide in their plasma high at the time of arrhythmia. Arrhythmogenesis remains a worrying effect of the drug that should be watched for carefully.

It is difficult to assess accurately the plasma concentration of flecainide that was consistent with efficacy in our group of children because few suffered from incessant arrhythmia. However, we have no reason to conclude from this study that the target range for children differs substantially from that proposed in adult patients (that is $400-800 \mu \mathrm{g} / \mathrm{l}$ ).

Compared with data obtained after the administration of flecainide to adult volunteers ${ }^{10}$ or patients (data on file, Riker Laboratories Inc), our paediatric patient group showed a small decrease in the weight related volume of distribution of flecainide and a small increase in its total plasma clearance. The combined effect of these changes was to produce a considerable decrease in the elimination half life compared with adults and, clinically, this was the most important finding. There was a significant trend for the youngest children to have the shortest elimination half life. This was most noticeable if the data from the two patients in cardiac failure were omitted. Subsequent findings in one of these patients (patient 3) suggest that exclusion of these data is justified, because after oral treatment, when the patient was not in cardiac failure, the half life was considerably shorter and similar to the group median value.

On the basis of this study we recommend that an intravenous dose of flecainide of $2 \mathrm{mg} / \mathrm{kg}$ should be given over at least 10 minutes. In general an oral dose of about $6 \mathrm{mg} / \mathrm{kg} /$ day produces a plasma concentra- $\frac{7}{\mathrm{C}}$ tion within the therapeutic range accepted for adult patients and would be an appropriate starting dose. $\stackrel{\text { s }}{+}$ Higher doses may be required in small neonates ando the use of plasma concentration measurements would을 help to identify cases in which lack of efficacy is the $\frac{\bar{\omega}}{\vec{D}}$ result of underdosage. Treatment should be started $\stackrel{\mathbb{\Phi}}{\circ}$ in hospital so that arrhythmogenic effects can be identified and dealt with swiftly. Flecainide is a drug with great potential for the treatment of childhood. arrhythmias. A knowledge of the pharmacokinetics, $\vec{\omega}$ with careful attention to optimum dosing, may contribute to its safe use in this age group.

We thank Riker Laboratories for supplies of flecainide and financial support and the staff of the pharmacies and paediatric wards at the Brompton $\omega$ and St George's Hospitals for their invaluable assistance.

\section{References}

1 Estes MNA, Garan H, Ruskin JN. Electrophysiologicalo properties of flecainide acetate. Am J Cardiol. 1984;53:26B-9B.

2 Roden DM, Woosley RL. Drug therapy; flecainide. N Engl J Med 1986;315:36-41.

3 Nathan AW, Hellestrand KJ, Bexton RS, et al. Proarrhythmic effects of the new antiarrhythmic agentक्ष flecainide acetate. Am Heart $J$ 1984;107:222-8.

4 Till JA, Rowland E, Shinebourne EA, Ward DE. $\overrightarrow{0}$ Treatment of refractory supraventricular arrhyth- 3 mias with flecainide acetate. Arch Dis Child 1987;62:247-52.

5 Wren C, Campbell RWF. The response of paediatric arrhythmias to intravenous and oral flecainide. Br Heart J 1987;57:171-5.

6 Bhamra RK, Flanagan RJ, Holt DW. High-O performance liquid chromatographic method for the measurement of mexiletine and flecainide in blood,, plasma or serum. J Chromatogr 1984;307:439-44.

7 Johnston A, Woollard RC. STRIPE: an interactiveo computer program for the analysis of drug pharmacokinetics. J Pharmacol Methods 1984;9:193-9.

8 De Paolo AAV, Horowitz LN, Morganroth J, et al. Influence of left ventricular dysfunction on flecainide $N$ therapy. J Am Coll Cardiol 1987;9:163-8.

9 Morganroth J, Anderson JL, Gentzkow GD. Classifica- ${ }^{\circ}$ tion by type of ventricular arrhythmia predicts $\omega$ frequency of adverse cardiac events from flecainide $J$ Am Coll Cardiol 1986;8:607-15.

10 Johnston A, Warrington S, Turner P. Flecainide pharmacokinetics in healthy volunteers: the influences? of urinary pH. Br J Clin Pharmacol 1985;20:333-8.

\section{Addendum}

Our study was undertaken before the preliminary 
results of the Cardiac Arrhythmia Suppression trial, Our study, however, was of a very different populaby the National Heart Lung and Blood Institute in tion-children with supraventricular tachycardiathe United States, became known. As a result of the and there is no evidence that the results of the Cardiac Arrhythmia Suppression trial the Committee on Safety of Medicines in the United Kingdom has restricted the use of flecainide, at present, to lifethreatening ventricular or junctional tachycardias.

Cardiac Arrhythmia Suppression trial can be directly extrapolated to our population. Our patients will be followed as part of a prospective study on the safety of class Ic antiarrhythmic drugs in infants and children. 